\title{
Oral health behaviours in relation to caries and gingivitis in primary-school children in Tehran, 2008
}

Mah. Jessri', Mar. Jessri², B. Rashidkhani ${ }^{3}$ and S-M. Kimiagar ${ }^{4}$

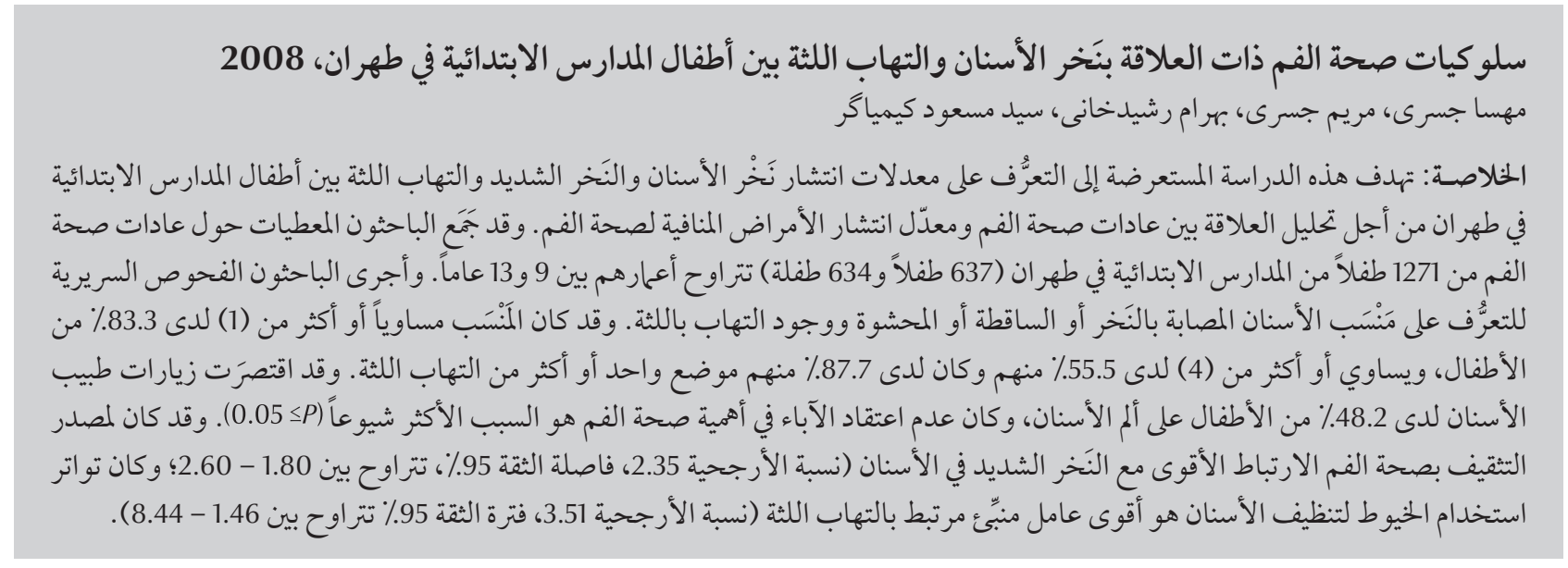

ABSTRACT The objectives of this cross-sectional study were to determine the prevalence of caries, severe caries and gingivitis in Tehran primary-school children and to analyse the relationship between children's oral hygiene habits and prevalence of these oral health diseases. Data were collected on the oral hygiene habits of 1271 Tehran schoolchildren (637 boys, 634 girls) aged 9-13 years. Clinical examinations were performed to determine the decayed, missed and filled teeth (DMFT) and the presence of gingivitis. Total DMFT $\geq 1$ was observed in $83.3 \%$ of children; $55.5 \%$ had tDMFT $\geq 4$ and $87.7 \%$ had $\geq 1$ site affected by gingivitis. Dental visits of $48.2 \%$ of children were limited to toothache occasions and parents' lack of belief in the importance of oral health was the most commonly cited reason $(P \leq 0.05)$. The source of oral health education had the strongest independent association with severe dental caries $(\mathrm{OR}=2.35 ; 95 \% \mathrm{Cl}: 1.80$ 2.60); dental flossing frequency was the strongest predicting factor correlated with gingivitis $(\mathrm{OR}=3.51 ; \mathrm{Cl}: 1.46-8.44)$.

Comportements en santé bucco-dentaire associés aux caries et aux gingivites chez des enfants du primaire à Téhéran en 2008

RÉSUMÉ Les objectifs de la présente étude transversale étaient de déterminer la prévalence des caries, des caries sévères et des gingivites chez des enfants du primaire à Téhéran et d'analyser la relation entre les habitudes d'hygiène bucco-dentaire des enfants et la prévalence de ces maladies bucco-dentaires. Des données sur les habitudes d'hygiène bucco-dentaire de 1271 écoliers de Téhéran (637 garçons, 634 filles) âgés de 9 à 13 ans ont été recueillies. Des examens cliniques ont été réalisés afin de repérer les dents cariées, absentes ou obturées (CAO) et la présence de gingivite. L'indice CAO global était supérieur ou égal à 1 chez 83,3\% des enfants, supérieur ou égal à 4 chez 55,5\% des enfants, et 87,7 \% d'entre eux avaient au moins un site affecté par une gingivite. Pour 48,2 \% des enfants, les visites chez le dentiste se bornaient à la prise en charge des douleurs dentaires. La méconnaissance des parents sur l'importance de la santé bucco-dentaire était la raison la plus fréquemment citée $(P \leq 0,05)$. La source de l'éducation bucco-dentaire était le facteur indépendant le plus souvent associé aux caries dentaires sévères $(O R=2,35$; IC à $95 \%: 1,80-2,60)$; la fréquence de l'utilisation du fil dentaire était le facteur prédictif le plus important corrélé à une gingivite $(O R=3,51 ; I C: 1,46-8,44)$.

${ }^{1}$ Department of Nutritional Sciences, Faculty of Medicine, University of Toronto, Toronto, Ontario, Canada. ${ }^{2}$ Oral Cancer Research Group, University of Queensland Centre for Clinical Research, Royal Brisbane and Women's Hospital, Brisbane, Queensland, Australia. ${ }^{3}$ Department of Community Nutrition; ${ }^{4}$ Department of Clinical Nutrition and Dietetics, Faculty of Nutrition Sciences and Food Technology, National Nutrition and Food Technology Research Institute, Shahid Beheshti University of Medical Sciences and Health Services, Tehran, Islamic Republic of Iran (Correspondence to B. Rashidkhani: b_rashidkhani@sbmu.ac.ir).

Received: 15/09/11; accepted: 12/12/11 


\section{Introduction}

Dental caries is one of the commonest chronic diseases with a varying occurrence pattern at a global level [1]. In most developed countries, the occurrence of dental caries is showing a declining rate in children [2]. This improvement can mainly be attributed to water fluoridation, oral health awareness, lower frequency of cariogenic food/drink intake and implementation of preventive programmes [2].

Despite the declining rate of caries occurrence in developed countries [2], surveys still suggest a high prevalence of this disease in Middle-Eastern children $[3,4]$. Studies carried out in this region have shown the rate of caries experience ranging from $62 \%$ to $74.8 \%$ for schoolchildren $[3,4]$.

The mean decayed, missing and filled tooth surfaces (DMFT) index in Iranian primary-school children was reported to be 3.54 in 2001 [5]. This was increased to 4.2 [standard deviation (SD) 2.9)] in boys and 3.4 (SD 2.6) in girls in a 2007 study [6].

Gingivitis is defined as reversible inflammation of gingival tissues characterized by swelling, bleeding, change in normal colour, and often sensitivity and tenderness [7]. The role of poor oral hygiene and dental plaque in gingivitis occurrence has been well established [7]. In contrast to many developed countries [8], high prevalence of gingivitis has been reported in Iranian children [9]. This has also been seen in Saudi Arabian studies investigating prevalence of gingivitis in children $[10,11]$.

Attempts have been made in a number of countries to explain the association between oral hygiene behaviours and oral health diseases in schoolchildren $[11,12]$. While such data would be invaluable in school-based oral health programmes, there appears to be no information available about Iranian children's oral hygiene behaviour and its relationship with oral health diseases. Therefore the aims of the present study were to evaluate the prevalence of the 2 commonest oral diseases (caries and gingivitis) in primary-school children and to analyse the relationship between oral health care habits of primary-school children and prevalence of caries and gingivitis.

\section{Method}

\section{Population and sampling}

The study was performed on 9-13-yearold children studying in public primary schools in Tehran in 2008. Ethical approval for the study was obtained from the ethics committee of Shahid Beheshti University and the Ministry of Education. Sixteen primary schools in Tehran city were selected using 2-stage cluster random sampling. In the primary sampling stage, we selected 4 districts of Tehran city to be representative of urban Tehran primary schools. We contacted the responsible authorities of the Ministry of Education in each district to obtain their approval. At the time of study all schools in Tehran were segregated. Lists of primary schools for boys and girls were prepared for each district. Two male primary schools and 2 female primary schools in each district were then chosen randomly, making up an overall total of 16 schools.

After obtaining the consent of the school managers for participation in our survey, they were asked to distribute an informed consent form to parents of all the 4th and 5th grade students. The parents were given a week to complete the forms. Of the 1632 potential participants, 79 parents contacted us using the phone number provided on the consent form and asked for further explanation about the nature and purpose of the study. The number of returned forms was 1299. However, 9 of the children refused to participate, and 19 were excluded because they had filled out the questionnaires either improperly or left some items unanswered. Thus, our final study population was 1271 (577 boys and 694 girls).

\section{Oral health assessment:}

Dental examinations were carried out in the classrooms under natural light and using disposable, plain, mouth mirrors and World Health Organization (WHO) Community Periodontal Index (CPI) probes. A single dentist, whose caries and gingivitis diagnoses were compared to those of an expert (kappa statistics for intra-examiner variability $=0.89$ ), conducted the clinical examinations. DMFT was calculated according to WHO criteria [13]. Lesions were diagnosed as dental caries when a carious cavity was present on visualization. If there was any doubt, the CPI probe was used to explore the surface. The surface was considered sound unless the probe point entered the cavity. Pits or fissures where the probe was caught were recorded only when there was additional visual evidence. No oral radiograph was taken and incipient caries were not recorded. The Löe and Silness gingival index was used to score gingivitis [14] on 6 surfaces (buccal surfaces of 16, 11, 26, 31, 36 and 41). Gingivitis was then computed as the number of affected sites. The children participating in the study were asked to complete an oral health questionnaire including multiple choice questions about the frequency of using dental floss, brushing and visiting a dentist. This questionnaire was designed based on a previous study [15]. It was translated into Farsi and back translated to check for accuracy. The translated questionnaire was piloted on a sample of 35 schoolchildren and the wording was modified slightly accordingly. We also asked the participants about the form of topical fluoride they used and how they applied it. Questions about other oral health habits were also included. The questionnaire was prepared in Farsi and tested in a pilot study on 35 children who were not part of the main investigation. Where necessary, modifications were made to the questionnaire before the commencement of the main study. 
All participants attended a 30-minute education session about "oral health and food choice" which was given after the examinations and the collection of the questionnaires.

\section{Statistical analysis}

All data were analysed and processed using SPSS, version 16.0. To test the difference between several means per category in each independent variable, we performed 1-way analysis of variance (ANOVA). $P$-value $\leq 0.05$ was considered significant.

To assess the association between the 3 outcomes (presence of dental caries, presence of severe caries, and gingivitis) and the independent variable (oral health behaviours) the chisquared test and Fisher's exact test were administered. All 3 outcomes were defined as dichotomous variables and children with more than 4 untreated decayed teeth were classed as having severe caries. Backward stepwise logistic regression was then used to determine variables that had an independent effect on the presence of the 3 outcomes and odds ratios were used to describe the impact of oral health behaviours on dental caries, severe caries and gingivitis.

\section{Results}

A total of 1271 primary-school children, 637 boys and 634 girls, aged $9-13$ years were included in the study. Mean age was 11.0 (SD 1.4) years. Prevalence of dental caries and the mean DMFT of the primary and permanent teeth among the children are presented in Table 1 . The overall prevalence of dental caries in primary dentition was $65.9 \%$ and the mean dmft was 2.30 (SD 2.42). For the permanent teeth, prevalence of dental caries was $70.2 \%$ and mean DMFT was 2.51 (SD 2.14). Mean dmft and caries prevalence decreased with age in the primary dentition, while mean DMFT in the permanent dentition increased with age.

Distribution of dental caries [total (t) $\mathrm{DMFT} \geq 1]$, severe dental caries $(\mathrm{tDMFT}>4)$ and gingivitis in relation to sociodemographic factors and oral hygiene behaviours are presented in Table 2. The proportion of children with $\mathrm{tDMFT} \geq 1$ was $83.8 \%$ (1066 of 1271); $55.5 \%$ of these (706 of 1271) had severe dental caries. Almost $90 \%$ of the children in our sample had $\geq 1$ sites affected with gingivitis. Mean $\mathrm{tDMFT}$ among the children was 4.81 (SD 4.21). The proportion of untreated caries in reported tDMFT was $85.14 \%$.

There was a statistically significant difference between the sexes in the proportion of children with caries, severe caries and gingivitis; with girls showing all 3 outcomes more than boys $(P \leq$ 0.05) (Table 2).
Slightly less than half the children ( $n$ $=612$ ) reported that their usual dental visits were limited to occasions when they had toothache (Table 2). Caries $(P \leq 0.05)$ and severe caries $(P<0.001)$ experience in these children were significantly high. Accordingly, the last dental visit was mainly a result of having toothache $(756 ; 59.5 \%)$. These children had significantly more dental caries $(P$ $<0.001)$ and severe dental caries $(P<$ $0.03)$ compared with their peers. The most common reason for not visiting the dentist was the parents' belief that their children's dental problem was not serious. The next most common reason was the children's own belief that their dental problem was not important. The children whose parents belief had prevented them from visiting the dentist experienced significantly more dental caries $(P<0.001)$ and gingivitis $(P<$ $0.013)$.

Five per cent $(5 \%)$ of the children reported that they never brushed their teeth; these children had significantly more dental caries $(P<0.001)$, severe caries $(P<0.001)$ and gingivitis $(P<$ $0.001)$ than others (Table 2).

Around half the children (47.52\%) reported that their school health educators had taught them how to brush (Table 2); in contrast only $10.62 \%$ had been taught to brush by their dentist. Children who learned how to brush from both their dentist and their health

\begin{tabular}{|c|c|c|c|c|c|c|}
\hline Age (years) & No. & $\begin{array}{c}\text { Primary dentition } \\
(\%)\end{array}$ & $\begin{array}{c}\text { dmft } \\
\text { Mean (SD) }\end{array}$ & $\begin{array}{c}\text { Permanent } \\
\text { dentition }^{\mathrm{b}, \mathrm{c}}(\%)\end{array}$ & $\begin{array}{c}\text { DMFT } \\
\text { Mean (SD) }\end{array}$ & $\begin{array}{c}\text { Gingivitis } \\
\text { (\%) }\end{array}$ \\
\hline 9 & 246 & 82.9 & $3.32(3.10)$ & 60.1 & $2.26(2.10)$ & 85.3 \\
\hline 10 & 268 & 70.9 & $2.80(2.61)$ & 62.9 & $2.40(2.60)$ & 81.3 \\
\hline 11 & 240 & 65.2 & $2.40(2.89)$ & 66.1 & $2.41(2.21)$ & 91.2 \\
\hline 12 & 270 & 59.5 & $1.60(1.67)$ & 73.0 & $2.86(2.50)$ & 88.5 \\
\hline 13 & 247 & 51.2 & $1.43(1.84)$ & 89.6 & $3.60(1.26)$ & 92.7 \\
\hline All & 1271 & 65.9 & $2.30(2.42)$ & 70.2 & $2.70(2.14)$ & 87.7 \\
\hline
\end{tabular}

aPrevalence of caries (decayed, extracted due to caries, and filled primary teeth).

${ }^{b}$ Prevalence of caries (decayed, missing, and filled permanent teeth).

'Statistically significant between age groups $(P \leq 0.05)$.

$d m f t / D M F T=$ decayed, missing and filled teeth; $S D=$ standard deviation 


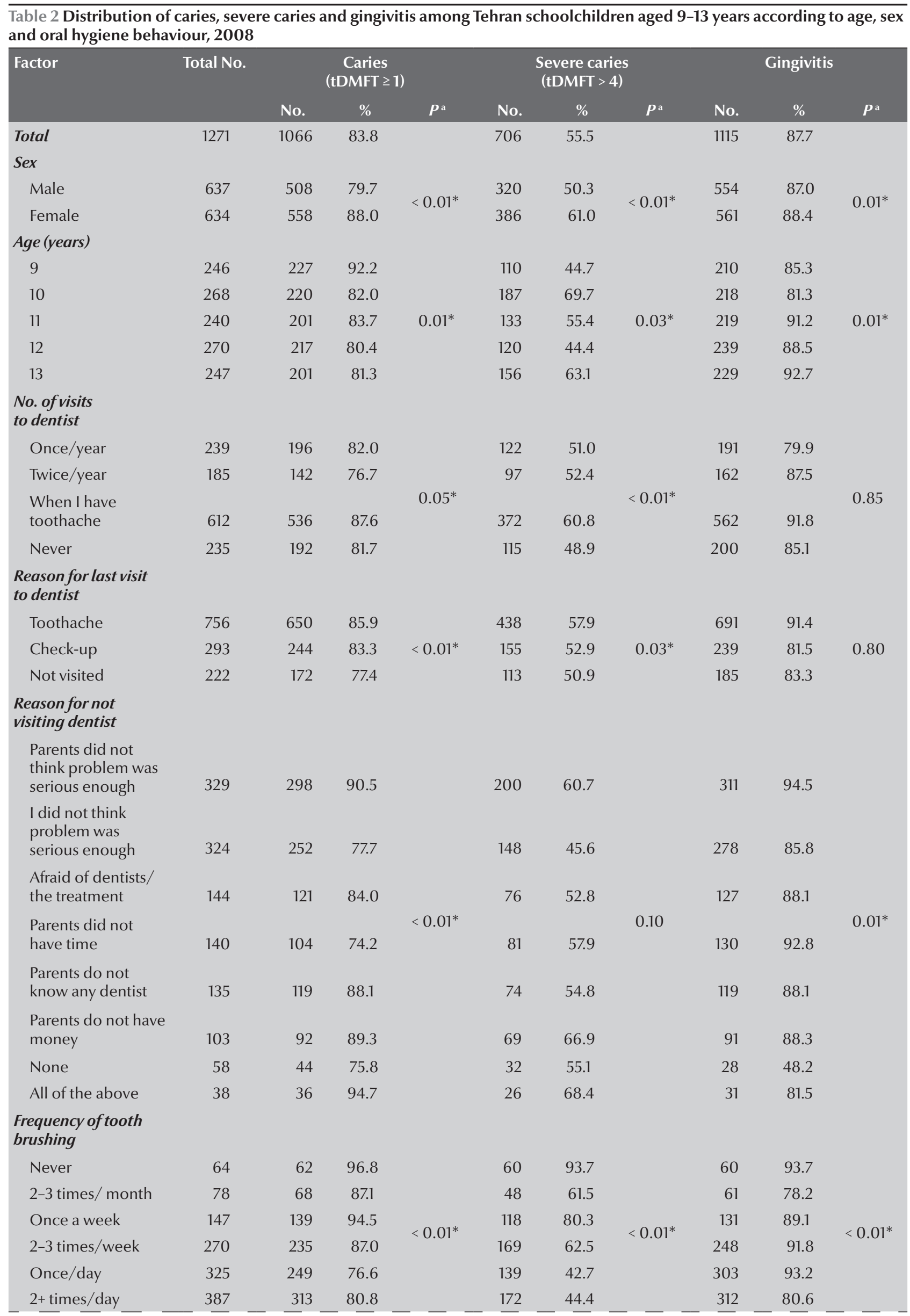




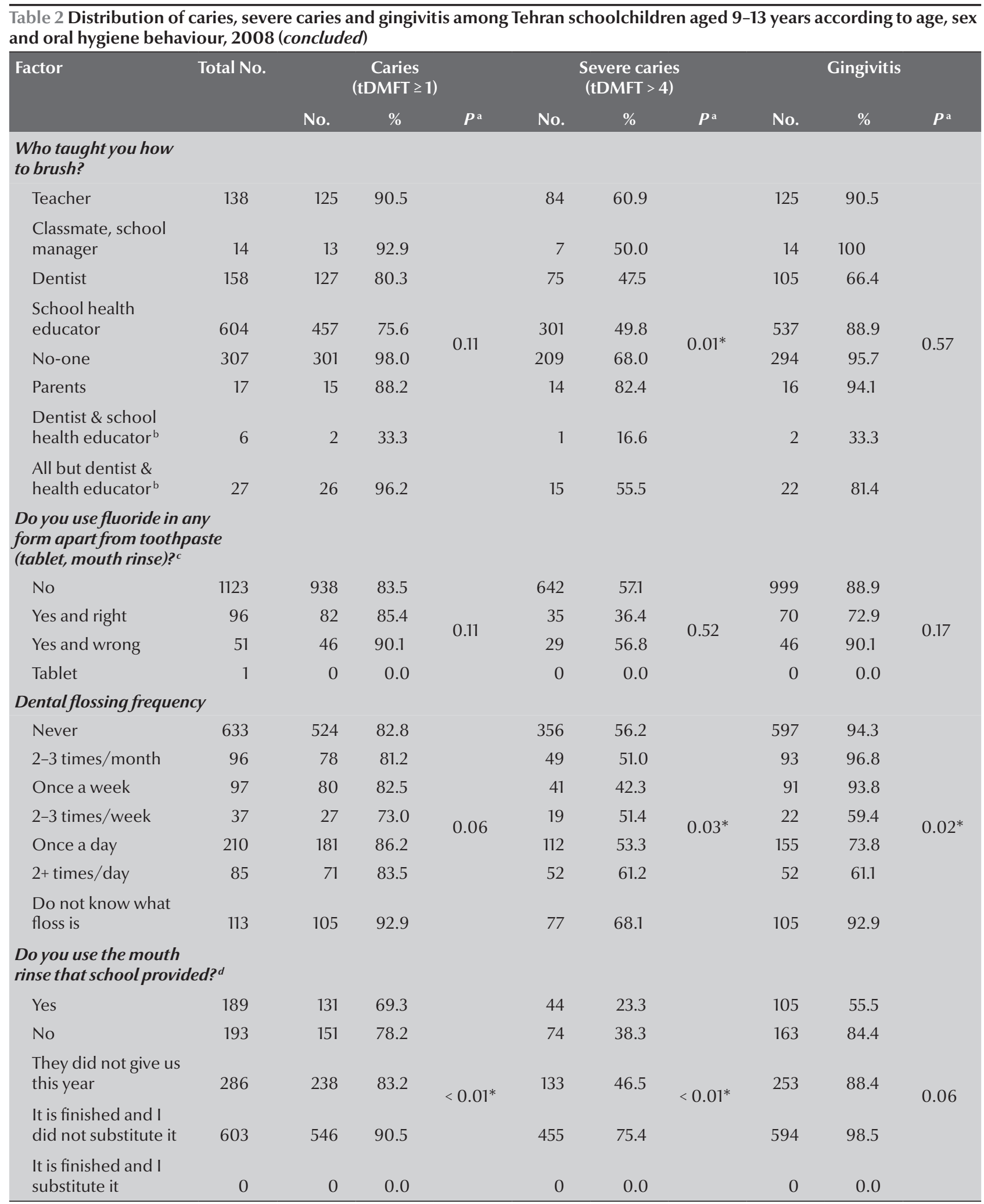

*Statistically significant at $P \leq 0.05$.

${ }^{a}$ Fisher's exact test was administered for the cells with less than 5 participants.

${ }^{b}$ This choice was added due to the children choosing more than one choice in replying to this question.

'This question was open ended in order to evaluate the application method of fluoride. The answers were read by a dentist and coded as: No = did not use fluoride in any form other than toothpaste; Yes and right= used fluoride and applied it appropriately; and Yes and wrong=used fluoride but the application method was inappropriate.

${ }^{d}$ The Iranian Ministry of health provides primary schools with mouth rinse each year.

tDMFT = total decayed, missing and filled teeth 
educators were less likely to be affected by severe dental caries $(P<0.001)$.

More than two-thirds of our participants (88.3\%) did not use fluoride in any form other than toothpaste (Table 2). Half the children (49.9\%) did not use dental floss at all and slightly less than half $(47.4 \%)$ reported they did not substitute the mouth rinse that school had provided them after finishing it.

To identify the factors contributing to the high prevalence of dental caries, severe dental caries and gingivitis, multivariate analysis was performed (Table 3). Six factors emerged as having an independently significant influence on occurrence of dental caries. For both severity of dental caries and gingivitis 4 factors emerged. Children who brushed their teeth once a week had almost 4 times the likelihood of experiencing dental caries and gingivitis compared to those who brushed their teeth $\geq 2$ times a day. The strongest association between severe dental caries and contributing factors was with the source of dental health education. Children who were not taught how to brush at all were more than twice as likely to experience severe dental caries as those who had been taught by their dentist. Likewise, children who did not have any idea what dental floss was were more than 3 times more prone to experiencing gingivitis than the other children (Table 3).

\section{Discussion}

The fact that more than two-thirds of the children in our study suffered from dental caries and gingivitis, and that slightly more than half had severe dental caries merits consideration. As almost $80 \%$ of our study population had at least 1 untreated decayed tooth, $\mathrm{D}$ was the major component of the tDMF score, indicating a high proportion of children in need of dental treatment.

We documented a higher mean DMFT compared to what was reported in a 2006 Iranian study on 12-year-olds
[16]. Part of this discrepancy could be ascribed to the different age groups studied, and the children in the 2006 study resided in Tehran and Isfahan, not Tehran only. However our findings are comparable with another 2006 study investigating dental health care in Tehran [17]. These results substantiate the concerns of the Iranian National Ministry of Health about the increasing rate of caries prevalence among Iranian adolescents [18].

The Tehran school-children in our survey had a gingivitis prevalence of $87.7 \%$. This falls between the $73 \%$ and $100 \%$ which were reported in 2 other major cities in the Islamic Republic of Iran $[5,9]$. Gingivitis prevalence of our study population was however lower than that seen in Saudi Arabia reported by Al-Banyan [10] and higher than what Guile, al-Shammary and el-Backly reported [11]. Overall, and despite the slight differences in gingivitis prevalence in Middle-Eastern countries, there is still a higher prevalence than in developed countries [8]. This condition necessitates the implementation of immediate therapeutic and preventive policies.

Multivariate analysis suggested that prevalence and severity of caries are affected by a number of oral health factors. Among these, lack of oral health education and infrequent tooth brushing were shown to have the strongest independent associations with severity and prevalence of dental caries, respectively. Also our results further suggested that using dental floss two or more times a day exerted an independent effect on prevention of gingivitis. Tooth brushing mode and frequency have been previously shown to alternatively influence caries severity and prevalence $[12,19]$ while our study suggests lack of oral health education to be the most effective factor in increasing the caries severity. This is simply explainable by knowing that children's mode of brushing is directly under the influence of oral health education [20]. A majority of study population reported they had learned brushing from their school health educator. In contrast, only 6 children reported that they were taught how to brush both from their dentist and their school health educators. Not surprisingly, among these children caries, severe dental caries and gingivitis prevalence were lowest among all.

Tehran's water supply is not fluoridated, and according to the American Academy of Pediatrics children residing in the communities with non-fluoridated drinking water are recommended to be given routine fluoride supplements [21]. Only 1 child reported using fluoride tablets as an auxiliary source, and slightly more than $5 \%$ of the children benefited from using mouthwashes with an appropriate method of application. This is an indicator that oral health education and intervention is necessary to establish correct oral health behaviour in this age group. The need for education is emphasized further when considering that almost $10 \%$ of the children did not have any idea about dental floss.

An association between caries severity and age, frequency of dental visits and frequency of brushing, although significant in bivariate analysis, failed to emerge in the multivariate model. Since these variables were proved to be strongly associated with caries prevalence, their effect could have been mediated through the effects of other variables such as sex, nutritional habits and oral health behaviours of the participants. Also, for frequency of dental visits, the effect could be influenced by the fact that the majority of our study population reported their dental visits to be limited to relief care instead of routine care or check-ups. The lack of relationship between sex and gingivitis in multivariate analysis, despite a significant relationship in the bivariate model, could also be the result of other interfering variables such as the difference in commitment to oral health behaviours in the 2 sexes. Other variables such as nutritional habits, frequency of brushing and application of fluoride and mouth 


\begin{tabular}{|c|c|c|c|}
\hline \multirow[t]{2}{*}{ Factor } & $\begin{array}{c}\text { Caries } \\
(\mathrm{tDMFT} \geq 1)\end{array}$ & $\begin{array}{l}\text { Severe caries } \\
(\mathrm{tDMFT}>4)\end{array}$ & Gingivitis \\
\hline & OR $(95 \% \mathrm{CI})$ & OR $(95 \% \mathrm{CI})$ & OR $(95 \% \mathrm{CI})$ \\
\hline Sex: male/female & $1.85(1.36-2.51)$ & $1.76(1.31-2.37)$ & \\
\hline Age: $<11 / \geq 11$ (years) & $0.672(0.49-0.91)$ & & $0.48(0.32-0.73)$ \\
\hline \multicolumn{4}{|l|}{ No. of visits to dentist } \\
\hline Twice a year/Toothache occasions & $1.59(1.01-2.52)$ & & \\
\hline Twice a year/Never & $1.55(1.03-2.34)$ & & \\
\hline \multicolumn{4}{|l|}{ Reason for not visiting dentist } \\
\hline None/Afraid of dentist or treatment & $1.34(1.14-1.86)$ & & $0.45(0.20-0.89)$ \\
\hline $\begin{array}{l}\text { None/I didn't think my dental trouble was } \\
\text { serious enough }\end{array}$ & $1.43(1.20-1.92)$ & & \\
\hline \multicolumn{4}{|l|}{ Frequency of tooth brushing } \\
\hline More than twice a day/once a week & $2.72(1.20-6.17)$ & & $2.87(1.06-8.25)$ \\
\hline More than twice a day $/ 2-3$ times a week & & & $0.02(0.01-0.15)$ \\
\hline \multicolumn{4}{|l|}{ Who taught you how to brush } \\
\hline Dentist/No-one & & $2.35(1.80-2.65)$ & \\
\hline \multicolumn{4}{|l|}{ Frequency offlossing } \\
\hline More than twice a day/Never & & $1.82(1.02-2.51)$ & \\
\hline $\begin{array}{l}\text { More than twice a day/Don't know what } \\
\text { dental floss is }\end{array}$ & & & $3.51(1.46-8.44)$ \\
\hline \multicolumn{4}{|l|}{$\begin{array}{l}\text { Do you use the mouth-rinse that school has } \\
\text { provided? }\end{array}$} \\
\hline Yes/No & & $1.70(1.03-2.81)$ & \\
\hline Yes/They did not give it out this year & $1.44(1.24-3.29)$ & $1.93(1.21-3.06)$ & \\
\hline Yes/It is finished and I did not substitute it & $1.73(1.10-2.72)$ & & \\
\hline
\end{tabular}

rinse could also serve as overwhelming factors.

During this investigation we faced this limitation that children may overreport their dental hygiene knowledge, attitudes and habits. In order to overcome this problem, we assured the children that their responses were confidential and would not influence their marks. The children had also received a demonstration on how to answer our multiple choice questions even though the 4th and 5th grade students are quite familiar with this type of questions.

This study showed a high prevalence of dental caries and gingivitis. This situation, along with the inadequate dental health services available for children demonstrates the necessity for urgent intervention both in terms of therapeutic and preventive policy makings.
Asking school health educators to have a more active role in dental health education and also educating parents about their children's oral health could be a first step towards oral health promotion. As suggested by Saied-Moallemi et al., better oral self-care among Iranian mothers is reflected in better oral health status and behaviour of their children [22], therefore mothers could potentially play a significant role in children's oral health, which should be taken into account in developing oral health programmes.

International health-promoting school programmes have suggested schools as a unique environment for development of regular oral health practices [23]. The experience of other Middle Eastern countries, e.g. Kuwait [24], should also be taken into account in order to benefit from the school setting as a platform to promote oral health care.

\section{Acknowledgements}

The authors would like to thank all students who participated in this study. We are grateful to Iranian Ministry of Education and school managers, especially Ms Shahla Jessri, Manager of 17-Shahrivar School, for their effective collaboration. We would also like to acknowledge the contribution and support of M. Jessri, J. Jessri and M. Khaki in the data collection, entry and cleaning process.

Funding : This study received funding from Shahid Beheshti University of Medical Sciences, Tehran.

Competing interests : None declared. 


\section{References}

1. Hugoson A, Koch G. Thirty year trends in the prevalence and distribution of dental caries in Swedish adults (1973-2003). Swedish Dental Journal, 2008, 32:57-67.

2. Williamson DD, Narendran S, Gray WG. Dental caries trends in primary teeth among third-grade children in Harris County, Texas. Pediatric Dentistry, 2008, 30(2):129-133.

3. Ahmed NA et al. Dental caries prevalence and risk factors among 12-year old schoolchildren from Baghdad, Iraq: a postwar survey. International Dental Journal, 2007, 57:36-44.

4. Sayegh A et al. Food and drink consumption, sociodemographic factors and dental caries in 4-5-year-old children in Amman, Jordan. British Dental Journal, 2002, 193(1):37-42.

5. Kazerouni $\mathrm{K}$ et al. [The effects of socio-economic status on dental caries indices in a group of primary school children, Tehran-2000]. Beheshti University Dental Journal, 2005, 22(Special Issue):51-59 [in Farsi].

6. Meyer-Lueckel $\mathrm{H}$ et al. Prevalence of caries and fluorosis in adf olescents in Iran. Quintessence International, 2007, 38(6):459465.

7. Newman MG et al., eds. Carranza's clinical periodontology, 10th ed. St Louis, Elsevier, 2006, Chapter 21.

8. Abrahamsson $\mathrm{KH}$ et al. Periodontal conditions in a Swedish city population of adolescents: a cross-sectional study. Swedish Dental Journal, 2006, 30:25-34.

9. Talebiardakani MR et al. [Evaluation of prevalence of gingivitis in students of 8-11 years of Yazd in primary school in 1379 (research)]. Majallah-i-Dandanpizishki, 2003, 15(2(45)):50-60 [in Farsi].

10. Al-Banyan RA et al. Oral health survey of 5-12-year-old children of National Guard employees in Riyadh, Saudi Arabia. International Journal of Paediatric Dentistry, 2000, 10(1):39-45.

11. Guile EE, al-Shammary A, el-Backly M. Prevalence and severity of periodontal diseases in Saudi Arabian schoolchildren aged 6, 9 and 12 years. Community Dental Health, 1990, 7:429-432.

12. Jamieson LM, Thomson WM, McGee R. Caries prevalence and severity in urban Fijian school children. International Journal of Paediatric Dentistry, 2004, 14(1):34-40.

13. Hobdell M et al. Global goals for oral health 2020. International Dental Journal, 2003, 53:285-288 (http://www.who. int/oral_health/media/en/orh_goals_2020.pdf, accessed 12 April 2013).
14. Löe H, Silness J. Periodontal disease in pregnancy. I. Prevalence and severity. Acta Odontologica Scandinavica, 1963, 21:533-551.

15. Yabao RN et al. Prevalence of dental caries and sugar consumption among 6-12-y-old schoolchildren in La Trinidad, Benguet, Philippines. European Journal of Clinical Nutrition, 2005, 59(12):1429-1438.

16. Momeni A, Mardi M, Pieper K. Caries prevalence and treatment needs of 12-year-old children in the Islamic Republic of Iran. Medical Principles and Practice, 2006, 15:24-28.

17. Saied-Moallemi $Z$ et al. Disparities in oral health of children in Tehran, Iran. European Archives of Paediatric Dentistry, 2006, 7(4):262-264.

18. [Plans and Programs of Dental Health Unit]. Tehran, Iranian Ministry of Health [in Farsi] (http://old.sbmu.ac.ir/SiteDirectory/Vice-ChancellorHealth/Pages/Oral_Health_Plans.aspx, accessed 12 April 2013).

19. Jamieson LM, Thomson WM. Dental health of Chatham Islanders: an investigation of the oral health of Chatham Islands residents. New Zealand Dental Journal, 2003, 99(4):90-97.

20. Kuriakose $S$, Joseph E. Caries prevalence and its relation to socio-economic status and oral hygiene practices in 600 preschool children of Kerala-India. Journal of the Indian Society of Pedodontics and Preventive Dentistry, 1999, 17(3):97-100.

21. Mahan LK, Scott-Stump S. Krause's food \& nutrition therapy, 12th ed. St Louis, Elsevier, Health Sciences Division, 2008, Chapter 7:228.

22. Saied-Moallemi $Z$ et al. Oral health behaviour of Iranian mothe ers and their 9-year-old children. Oral Health \& Preventive Dentistry, 2007, 5(4):263-269.

23. Peterson PE, Christensen LB. Oral health promotion. Health promoting schools project. Copenhagen, World Health Organization Regional Office for Europe, 1994.

24. Vigild $\mathrm{M}$ et al. An oral health programme for school children in Kuwait, 1986-97. Community Dental Health, 1999, 16:102-106. 